intensified when combined with the ortho-acid, and still more $\therefore$ o when incorporated with this acid and salicylic acid.

The question which has been raised as to the therapeutic value of the sodium salt of para-cresotic acid is beyond the scope of this research. The acid from which it is prepared is poisonous, yet its salt, judiciously given, may be of benefit in certain diseases. The information as yet afforded with regard to this is meagre, and requires to be supplemented; but whatever the decision as to its value may be, the presence of para-cresotic acid cannot be desired by anyone who impartially considers the subject from a chemical, a physiological, or a therapeutic standpoint.

\section{A CASE OF ACROMEGALY.}

BY ROBERT RUTTLE, I.M.\& S.UNIV.Deb., Vice-President Blackburn and District Medical Society.

THE first of the accompanying photographs is that of the patient just before her marriage in 1876 ; at that time she was 24 years of age. The second, taken recently in the same position, affords a striking contrast.

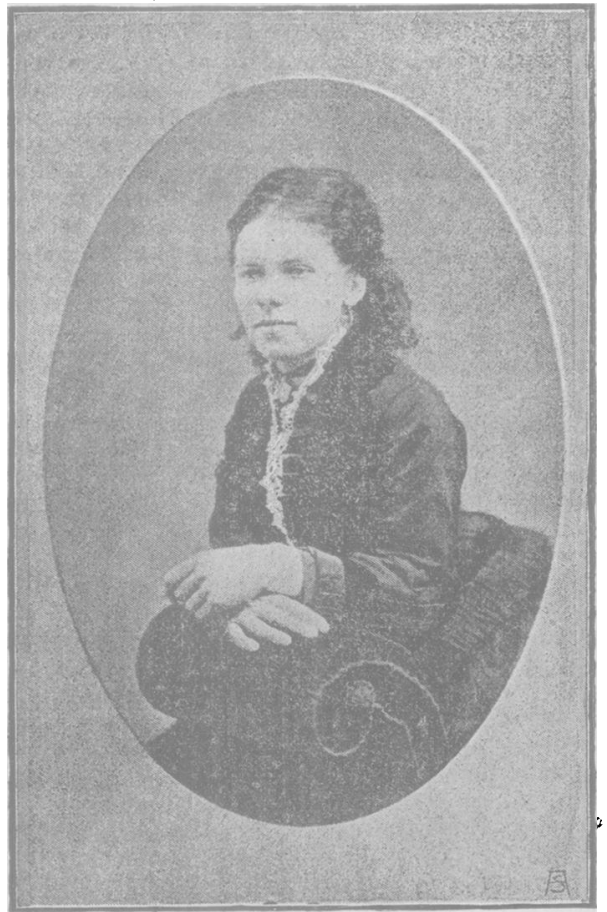

A. HI., 1876 .

I saw the patient in May, 1879. She was not then or since until October 11th, 1890, a patient of mine, but at that casual moeting lier face, hands. and fect at once attracted my attention. I thought of cretinism, but the woman was clear, cool, intelligent, though certainly in a peculiar condition, and she let fall the remark that she had been under Dr. Popjoy for a (*)nsiderable time. She is now 38 , has been married fourteen years, has had no family. She had been accustomed to heavy farm service, describes herself as "strong and healthy, with "heeks like roses," up to the time of first symptoms. She had no severe illness nor any irregularity, except that her menstrual periodicity varied sliglitly, but without pain or any other inconvenience: she menstruated once after marriage, never since then. Soon after she began to experience severe pains about vertex, back of head, and in the cervical region, which increased gradually in intensity; she also complained of a feeling of "numbness" all over her body; the headache became "dreadful," and she then noticed that her hands and feet were "swelling," hecause No. 7 gloves no longer fitted her

1 s hown at the Blackburn and District Medical Society. hands, and 5 in boots also became too small. This enlargement went on gradually. When she was twelve months married she was suddenly seized in the mill with an at tack of vertigo followed by total loss of consciousness. She was taken to a friend's house, and from there removed home with difficulty, kept her bed for nearly three weeks, hanging apparently between life and death. Her convalescence was slow, alternating with relapses of agonising pain, accompanied by vertigo and loss of consciousness. These attacks seem of late years to have somewhat decreased in severity. Treatment always was powerless to relieve her, rest and quiet alone doing any good; she appeared better when idle in the country.

At the time of the severe explosion her extremities rapidly enlarged, so much so that her left ring finger burst her wedding ring, a moderately stout one. She also began to experience failure of sight at this time, which has gone on to total blindness in the right eye from atrophy of the optic nerve. In the left eye the temporal half of the field of vision is gone, and the activity of the upper limit at the nasal side slightly encroached on; the hemianopsia is very clearly defined; refraction is emmetropic, the pupils always somewhat dilated; the optic axes are divergent.

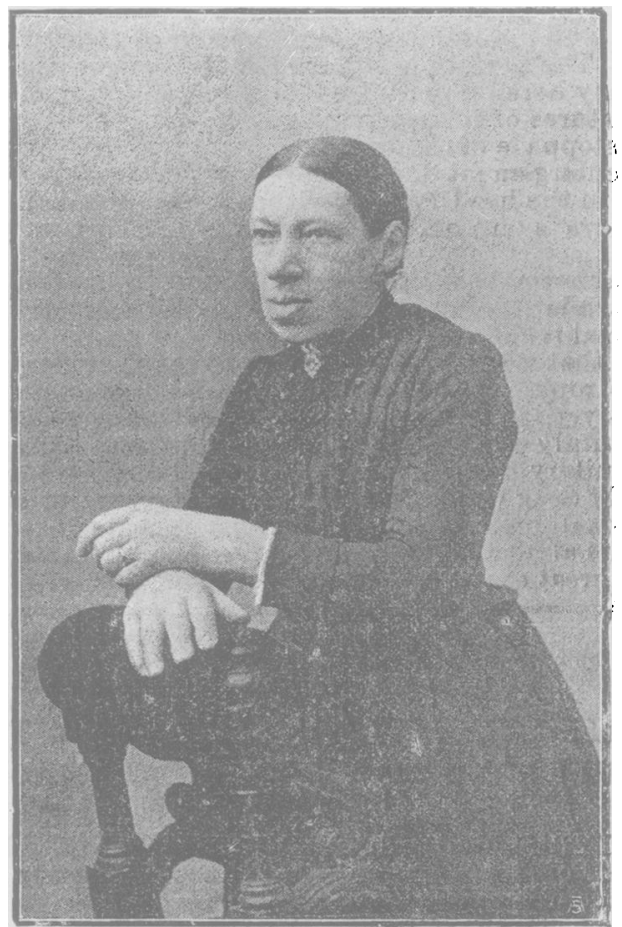

A. H., November, 1890 .

Heart, liver, kidneys, etc., appear sound, no albumen or sugar present; occasionally a slight cloud of phosphates in urine.

Digestion fairly good, bowels inclined to constipation; she eats little, often not till evening. She can sleep well, but wakens often during the night. I might add that her pain now generally comes on at night and wakens her; but sleep and rest afford relief, stimulants rather increase pain. She does not use tea. Coffee gives some slight relief; coffee and cocoa are her usual beverages.

Her face is pale, with skin smooth and few wrinkles, but not very marked; slight puffiness under lower lids certainly varies, while eyes are somewhat divergent and lids large the cartilages are enlarged, nose long and very large; both lips hypertrophied, especially the lower one; the lower jaw and chin enlarged, prominent, prognathous; teeth separated, tongue large; the face does not appear at all broadened nor the frontal sinuses enlarged. Her head measures 23 . inches in circumference round the brows.

She has become somewhat stooped, and complains of 
sciatic pains, especially on the left side, which compel her to walk lamely. Her left hand measures 81 inches in length and is 83 inches round the knuckles; the second joint of left forefinger is $3 \frac{1}{1}$ inches in circumference; no women's gloves or boots fit her; she wears $8 \frac{1}{2}$ boots. She can now close her hand and make a fist. Both radius and ulna are enlarged, so are the malleoli and head of tibia. The vertebræ appear normal in size, but the sternum is certainly larger than normal ; the pelvis also is certainly larger, the ileum feeling most massive. She says she "hardly had any hips before." She has had dyspareunia for two years; the vaginal orifice appears contracted spasmodically, though it allowed the passage of the finger, when the os tincæ and the canal of the vagina appeared normal. She had slight eczema of external auditory meatus, but no appreciable enlargement of the ears. She complains of great sensitiveness over the lower cervical and first dorsal vertebræ. A playful slap on the shoulders has often produced unconsciousness. She cannot bear the least noise; a sudden noise as of a door slamming will often act like a blow.

I can elicit no family history of gout, syphilis, or tubercle. Her father is still living; her mother died at 68 ; brothers and sisters are healthy. Her intelligence is clear, and quite above the average of women in the lower stratum of midland rural life. She presents no deterioration of faculty save that of sight. The thyroid is enlarged, and I believe the thymus also. I may here be permitted to point out the most noteworthy features of this particular case:-

1. The stoppage of catamenia.

2 . The enlargement of extremities without pain.

3. Pain in the head (vertex without enlargement).

4. The eye symptoms: R, atrophy; I, temporal hemianopsia.

5. The abnormal sensitiveness to sound.

6. The tenderness and sensitiveness over her cervical and upper dorsal regions.

I think that we have here enough to point to derangement of a neurotrophic character, of the precise characters of which we are as yet, I fear, ignorant. The atrophy and hemianopsia certainly favour Dr. Marie's views respecting an enlarged pituitary body.

The only drug which I have found to give her any relief has been exalgine, in doses of 3 grains repeated every eighth hour. This almost completely relieves the migraine, and has given her great ease from the sciatic pain.

\section{MEMORANDA: \\ MEDICAL, SURGICAL, OBSTETRICAL, THERA- PEUTICAL, PATHOLOGICAL, ETc.}

PERITYPHLITIS COMPLICATING TONSILLITIS.

This case is of interest, as it bears on the comnection between these two complaints.

Mrs. F., aged 63. taken with the ordinary signs of acute tonsillitis on November 5 th last. She was very had for a week, suffering from great weakness. The left tonsil was especially affected, and the olands along the front border of the lef sterno-mastoid were swollen and tender for some fourteen days. On November 19th she complained of severe intermittent pain along the brim of the pelvis on the right side to the anterior superior spine. There was great tenderness along the region of the transverse colon, and the flanks were dull to percussion. On the 21st there was a well-defined tumour $1 \frac{1}{2}$ inch in diameter, whose edge was $\frac{1}{2}$ inch from the anterior superior spine: it was dull to percussion. The pain extended to the front of the right knee, and she had some trouble in micturating. On the 22nd, as previously, she complained much of the free perspiration, and now had erythema of the face and forehead. Up to December 1st she suffered from pain down the leg; the tenderness lasted till November 27th. She suffers from aortic regurgitation and stemosis, is liable to attacks of acute hronchitis, and was attended by me in 1887 for acute tonsillitis.

Queen's Ciescent, N.W.
ANALYSIS OF THE FREQUENCY OF SYMPTOMS OCCURRING IN 50 CASES OF GERMAN MEASLES.

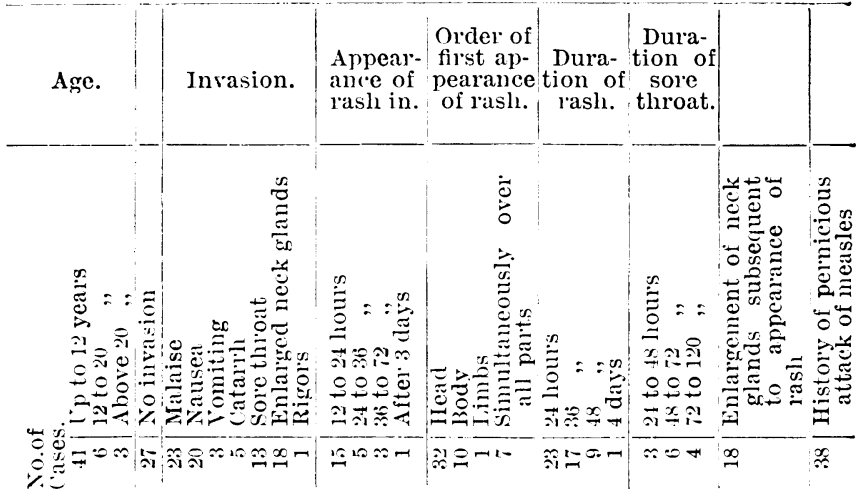

This epidemic was evidently of mild type. The throat symptoms were mild in all cases. The rash appeared to be thicker and darker in proportion to age. In no case did the rash assume definitely the crescentic form seen in measles. In young fair patients having a mild attack the rash appeared particularly like that of scarlatina at its commencement, and was in some cases accompanied by a temperature of $103^{\circ} \mathrm{F}$. One case ushered in by rigors and other severe symptoms, in which the rash did not appear for three days, remained four days and did not assume a crescentic form, may have been measles, but occurred in a house with other cases of rötheln. Enlargement of the neck glands will be seen to be a valuable diagnostic point.

Hednesford.

Cecil Digbr, M.D.

\section{CO-EXISTENCE OF SCARLET FEVER ANI)} CHICKEN-POX

Ox January 9th last, I was asked to see L. N. and G. N., both suffering from well marked symptoms of scarlet fever. 'They both had a temperature of over $102^{\circ}$, sore throat, typical tongue and rash, L. having been taken ill on January 7 th, and $G$. on the 8 th

On January 10th, F. N., another brother was attacked. The three children were isolated, the remaining child of the family not contracting the disease. The fever ran an ordinary and favourable course, peeling commencing freely around the neck, chin and chest, in I. and G., on my visit to them on January 14th. On January 16 th my attention was especially directed to $G$., who was said to have been feverish and complaining of headache, sickness, and general malaise on the morning of the previous day (15th), a few ill-defined spot appearing on his body in the evening, but who at the time of my visit presented all the characteristics of a severe attack of chicken-pox. Not only had he a very numerous crop of vesicles all over his body, scalp, and face, but on his tongue and soft palate, causing considerable difficulty in deglutition. He, however, recovered, together with his brother and sister, without any other unfavourable symptom, differing in no respect from them, except that in his case the peeling process was rather delayed.

On January 28 th, or exactly thirteen days after G., F. was attacked with chicken-pox, the sister up to the present escaping. The children I found had been attending a public elementary school in which there had certainly been one if not more cases of scarlet fever, and several of chicken-pox, and had doubtless contracted both diseases there, G. probably catching the chicken-pox on the 2 nd, and scarlet fever on or about the 5 th.

It must remain a matter of conjecture how far the fact of having the specific poison of one disease in the system affected the course or seriousness of the other; it is plain $t$ lat having one disease did not prevent him catching another ; the second disease (scarlet fever) remaining as in the other children of the "benign" type.

The chicken-pox, on the other hand, was decidedly severe, especially if judged by the character of F.'s attack (which did not develop until eighteen days after the scarlet fever, and was mild and with slight eruption), but whether this 